\title{
EFEITO DO AIB SOBRE A QUALIDADE E FITOSSANIDADE DOS ALPORQUES DE INFLUÊNCIA DA Caryocar brasiliense Camb (CARYOCARACEAE) ${ }^{1}$
}

\author{
Germano Leão Demolin Leite ${ }^{2}$, Ronnie Von dos Santos Veloso ${ }^{2}$, Ana Carolina Ribeiro de Castro ${ }^{2}$, Paulo \\ Sérgio Nascimento Lopes ${ }^{2}$ e Geraldo Wilson Fernandes ${ }^{3}$
}

\begin{abstract}
RESUMO - O objetivo deste estudo foi testar a influência de quatro concentrações do hormônio vegetal ácido indolbutírico (AIB) $(0,500,1.000$ e 2.000 ppm) na obtenção de alporques de Caryocar brasiliense Camb (Caryocaraceae) fitossanitariamente adequados. Avaliou-se o efeito direto desse hormônio na indução de galha por Eurytoma sp. (Hymenoptera: Eurytomidae) nas folhas dos alporques, bem como o seu efeito indireto sobre os parasitóides de Eurytoma sp. O delineamento experimental foi o inteiramente casualizado, com três repetições, cada parcela experimental com dois alporques, e cinco tratamentos: 1) sem anelamento; 2) anelado + 0 ppm de AIB; 3) anelado + 500 ppm de AIB; 4) anelado + $1.000 \mathrm{ppm}$ de AIB; e 5) anelado + $2.000 \mathrm{ppm}$ de AIB. Não houve diferença significativa $(\mathrm{p}>0,05)$ nas taxas de enraizamento dos alporques, de raízes/alporque, de comprimento da maior raiz/alporque, de taxas de calejamento e de sobrevivência dos ramos anelados. Também, não se verificou diferença estatística entre os tratamentos quanto ao número do parasitóide Quadrastichus sp. (Hymenoptera: Eulophidae) e das características morfológicas externas das galhas induzidas por Eurytoma sp. Entretanto, observaram-se efeito positivo entre as concentrações de AIB e o número de galhas e maior número de adultos de Eurytoma sp. e de seu principal parasitóide Sycophila sp. (Hymenoptera: Eurytomidae) na concentração de 2.000 ppm de AIB. Esses dados indicam que esse galhador pode selecionar partes da planta ou plantas com maior concentração de hormônio. Devido à baixa efetividade desse hormônio na produção de estacas para a propagação assexuada de C. brasiliense, mais estudos são necessários devido ao fato de esta ser uma das mais importantes espécies no bioma Cerrado. Estudos futuros também são necessários para elucidar o envolvimento do AIB na formação de galhas e o seu impacto indireto na comunidade de parasitóides associados.
\end{abstract}

Palavras-chave: Pequi, propagação vegetativa, galhas, Eurytomidae, Eulophidae, regulador de crescimento e ácido indolbutírico.

\section{EFFECT OF AIB ON QUALITY AND PHYTOSSANITY OF Caryocar brasiliense Camb (CARYOCARACEAE) AIR LAYERING}

\begin{abstract}
The aim of this study was to test the influence of indol butiric acid (IBA) at four levels (O, 500,1000 , and 2000 ppm) to obtain healthy air layering of Caryocar brasiliense Camb (Caryocaraceae). In addition, we also observed the direct effect of this hormone on the success of leaf gall induction by Eurytoma sp. (Hymenoptera: Eurytomidae), and its indirect effect on galling insect parasitoids. A complete randomized design was used, with three replicates of each plot containing two air layering, and five treatments: 1) no girdling, 2) girdled + Oppm IBA; 3) girdled + 500ppm IBA; 4) girdled + 1000ppm IBA, 5) girdled + 2000ppm $I B A$. The rates of air layering rooting, root/air layering, largest root length/air layering, callus formation and girdled shoots survival were not influenced by the different concentrations of IBA ( $p>0.05)$. Furthermore,
\end{abstract}

\footnotetext{
${ }^{1}$ Recebido em 03.10.2005 e aceito para publicação em 19.12.2006.

${ }^{2}$ Depto. de Fitotecnia do Núcleo de Ciências Agrárias da Universidade Federal de Minas Gerais - UFMG, Av. Osmani Barbosa s/n, B. JK, Montes Claros - MG, 39404-006, CP: 135. E-mail: <gldleite@ nca.ufmg.br>.

${ }^{3}$ Ecologia Evolutiva de Herbívoros Tropicais do Depto. do Instituto de Ciências Biológicas da UFMG, CP486, ICB/Universidade Federal de Minas Gerais, 30161-970, Belo Horizonte - MG.
} 
the number of the parasitoid Quadrastichus sp. (Hymenoptera: Eulophidae) and external morphological traits of the gall induced by Eurytoma sp. were not influenced by the different treatments. However, a positive relationship was found between IBA concentration and galls successfully induced, and between the number of adults of the galling Eurytoma sp. and its major parasitoid, Sycophila sp. (Hymenoptera: Eurytomidae) with 2.000ppm of IBA. These data indicate that the galling insect may select plant modules or plants with higher hormone concentration and that IBA may play a role in gall induction. Due to the low success of this hormone in the asexual propagation of $\boldsymbol{C}$. brasiliense more studies are needed as this plant is one of the most important species in the Brazilian woodland savanna biome. Further studies are also needed to address hormone role in gall formation and its indirect effect on the community of associated parasitoids.

Keywords: Pequi, vegetative propagation, galls, Eurytomidae, Eulophidae, growth regulators and indol butiric acid.

\section{INTRODUÇÃO}

O pequizeiro, Caryocar brasiliense Camb. (Caryocaraceae), é uma árvore encontrada com abundância no Cerrado brasileiro e desempenha papel importante na economia de pequenas comunidades extrativistas devido ao seu emprego para extração de óleo, preparo de pratos típicos e também na indústria cosmética e para a produção de sabonetes e cremes (ARAÚJO, 1995; SILVA et al., 2001). Porém, a exploração extrativista intensiva da população tem dificultado sua regeneração natural, pois quase todos os frutos de pequi são coletados em função das elevadas cotações que têm recebido atualmente no mercado (MELO, 1987).

Uma possibilidade para o repovoamento ou para futuros cultivos comerciais de C. brasiliense é a produção de mudas em viveiros. Contudo, alguns fatores dificultam o cultivo do pequi, como a dormência natural das sementes, que, mesmo sendo tratadas com ácido giberélico, apresentam ainda baixa taxa de germinação, em torno de $50 \%$, e também a grande variação de qualidade das mudas propagadas por sementes (MELO, 1987; DOMBROSKI et al., 1998; PACHECO, 2002; PEREIRA et al., 2002). Dessa forma, com a restrição de germinação de sementes a propagação por enxertia fica limitada em função da dificuldade de obtenção do porta-enxerto. Outras formas de propagação assexual também têm sido testadas com pouco êxito, como a estaquia (FERNANDES et al., 2003) e a cultura de tecidos (LANDA et al., 2000).

Dentro desse contexto, torna-se importante buscar outras alternativas para a propagação da espécie, como a utilização da técnica de alporquia, por ser uma propagação assexual que apresenta grande sucesso em plantas que demonstram grandes dificuldades para emissão de raízes adventícias (HARTMANN e KESTER, 1990).

A alporquia consiste na retirada de uma porção da circunferência da casca de galhos, de forma a expor um anel do tecido interno, sobre o qual se adiciona uma quantidade de substrato umedecido, recoberto por filme plástico. Nessa região, em razão da retirada da casca, acumulam-se auxinas, co-fatores de enraizamento e fotoassimilados, que em conjunto com a aplicação exógena de reguladores de crescimento, como o ácido indolbutírico (AIB), são fatores importantes para promover o enraizamento adventício (HARTMANN e KESTER, 1990).

C. brasiliense apresenta fauna rica em invertebrados associados, incluindo várias espécies de insetos indutores de galhas, como aqueles da espécie Eurytoma sp. (Hymenoptera: Eurytomidae), cujo ataque pode induzir a queda prematura das folhas desses indivíduos (OLIVEIRA, 1997), reduzindo a sua produtividade. Além do impacto no redirecionamento de fotoassimilados, esse galhador pode até mesmo reduzir o sucesso na formação das mudas por meio de alporquia, por reduzir a área fotossintética e, ou, contaminar as futuras mudas que irão para o viveiro de plantas ou para o campo definitivo de plantio.

De acordo com o que foi exposto, o AIB pode estar envolvido em dois mecanismos fisiológicos distintos: a indução de formação de raízes adventícias e a formação de galhas. Assim, a utilização de AIB em técnicas de reprodução assexuada pode trazer como conseqüência o aumento indesejado do ataque de insetos galhadores de folhas.

Embora haja pouca informação sobre os mecanismos pelos quais alguns taxa de insetos são capazes de 
induzir galhas, sabe-se que em alguns casos eles podem produzir hormônios vegetais, principalmente auxinas, e, ou, mesmo seqüestrar hormônios da planta hospedeira para a formação dessas estruturas (WEIS et al., 1989; ALONI, 1995; MAPES e DAVIES, 2001), como ocorre com Eurosta solidaginis Fitch (Diptera: Tephritidae), inseto galhador de Solidago altissima L. (Asteraceae), que sintetiza ácido indolacético (AIA). Mapes e Davies (2001) removeram o ápice caulinar da S. altissima, sendo observado que as galhas de E. solidaginis continuaram o seu desenvolvimento, e a maior concentração de AIA nos tecidos das galhas ocorre no início da formação destas. Outra auxina, o ácido indolbutírico (AIB), também pode afetar positivamente a formação das galhas, como foi verificado em raízes danificadas de Prunus cerasifera L. (Rosaceae), que produziram AIB aumentando o desenvolvimento de galhas do nematóide Meloidogyne arenaria (Neal) (Heteroderidae) (ESMENJAUD et al., 1995).

Há vários trabalhos evidenciando que os insetos galhadores são comumente parasitados, chegando, em alguns casos, a $80 \%$ de mortalidade das galhas (FERNANDES et al., 1999; KATIYAR et al., 2000; ELIASON e POTTER, 2001). Devido a essa associação, é provável que fatores externos que afetam o hospedeiro, como hormônios vegetais, também possuem afetar os parasitóides.

O objetivo deste trabalho foi testar as seguintes hipóteses, relativas à produção de alporques fitossanitariamente adequados em pequizeiro: 1) há correlação positiva entre o aumento da concentração de AIB aplicado na alporquia e a formação e o desenvolvimento de raízes adventícias; 2) há correlação positiva entre o aumento da concentração de AIB e o número e o desenvolvimento de galhas foliares; e 3) há correlação positiva entre o aumento da concentração de AIB e o ataque de parasitóides às galhas.

\section{MATERIAL E MÉTODOS}

O experimento foi conduzido no Campus do Núcleo de Ciências Agrárias da Universidade Federal de Minas Gerais, em Montes Claros, Minas Gerais, Brasil, em dezembro de 2003 a março de 2004.

As alporquias foram realizadas em ramos semilenhosos, no $1^{\circ}$ nó imediatamente abaixo da região apical destes, em três pequizeiros em fase de produção, aplicando-se o regulador de crescimento AIB em mistura com lanolina nas áreas expostas do ramo anelado, envolvendo a região com musgo (Sphagnum sp. Sphagnaceae) umedecido (PACHECO et al., 1998). A região foi coberta com filme de polietileno (PVC), amarrando-se as extremidades para manutenção da umidade (PACHECO et al., 1998). Após três meses da realização da alporquia, foram avaliados a taxa de enraizamento, o comprimento da maior raiz/alporque e as taxas de calejamento e de sobrevivência dos ramos anelados.

O delineamento experimental adotado foi inteiramente casualizado, com três repetições, cada parcela experimental com dois alporques, e cinco tratamentos: 1) sem anelamento, 2) anelado +0 ppm de AIB; 3 ) anelado + 500 ppm de AIB; 4) anelado + 1.000 ppm de AIB; e 5) anelado + 2.000 ppm de AIB. Os dados foram submetidos às análises de variância e de regressão, todos a $5 \%$ de probabilidade.

Contaram-se, semanalmente, os números de adultos de Eurytoma sp. e de seus parasitóides Sycophila sp. (Hymenoptera: Eurytomidae) e Quadrastichus sp. (Hymenoptera: Eulophidae), de galhas presentes em um folíolo central (folha trilobada) da primeira folha da extremidade do galho com limbo foliar plenamente expandido/parcela. Avaliaram-se também a altura e diâmetro das galhas ( $\mathrm{mm}$ ) semanalmente, durante os três meses de experimento. Os dados foram submetidos às análises de variância e de regressão, todos a 5\% de probabilidade.

\section{RESULTADOS E DISCUSSÃO}

Não foi encontrada diferença estatisticamente significativa $(\mathrm{P}>0,05)$ nas taxas de calejamento $(79,16$ $\pm 8,46 \%)$ e enraizamento dos alporques $(8,33 \pm 5,76 \%)$ e sobrevivência dos ramos anelados $(62,50 \pm 10,09 \%)$, número de raízes/alporque $(0,83 \pm 0,65)$ e comprimento da maior raiz/alporque $(0,28 \pm 0,21 \mathrm{~cm})$ entre as diferentes concentrações de AIB (Figura 1). Contudo, foi observada uma tendência de maior porcentagem de calejamento nas concentrações de 500 ppm $(83,33 \pm 16,67 \%)$ e 1.000 ppm $(100,00 \pm 0,00 \%)$ de AIB. O enraizamento ocorreu apenas nas concentrações de 500 ppm $(16,67 \pm 16,67 \%)$ e $2.000(16,67 \pm 16,67 \%)$ ppm de AIB, sendo o maior comprimento $(0,77 \pm 0,77 \mathrm{~cm})$ e o número de raízes observados na maior concentração $(2,50 \pm 2,50)$. Na concentração de 500 ppm de AIB, observou-se maior sobrevivência dos ramos anelados $(83,33 \pm 16,67 \%)$

R. Árvore, Viçosa-MG, v.31, n.2, p.315-320, 2007 
(Figura 1). Apesar de ter apresentado uma taxa de enraizamento baixa, a alporquia apresenta potencial e deve ser investigada mais profundamente, testando épocas diferentes de alporquia, outras doses de AIB e outros reguladores de crescimento. Um dos fatores que interferem no sucesso da alporquia é a época da sua realização (ALMEIDA et al., 2004), que de forma
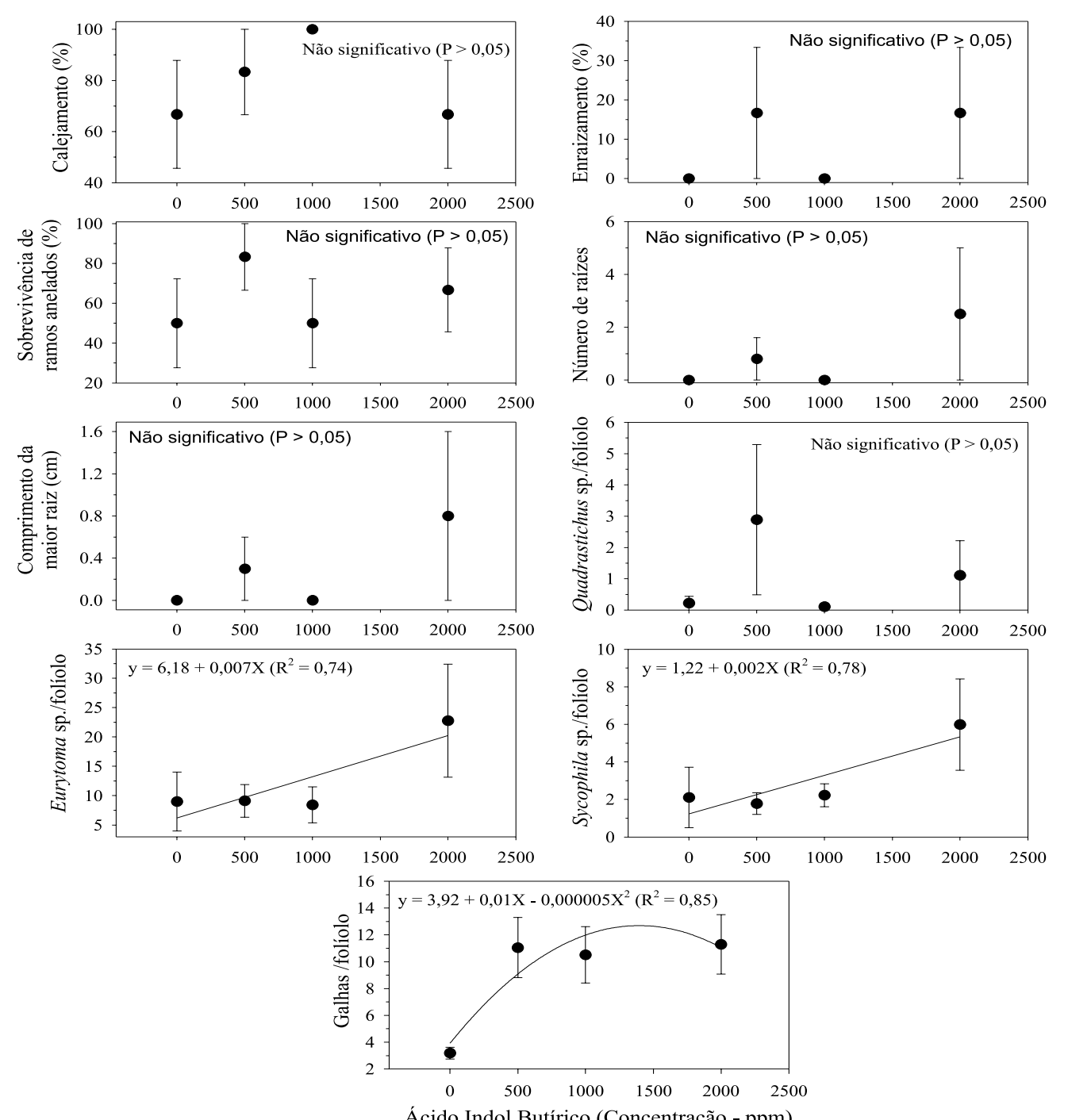

geral deve ser realizado na primavera-verão, em que os ramos estão em franco crescimento e com maior produção de carboidratos, auxinas e co-fatores de enraizamento (HARTMANN e KESTER, 1990). Porém, neste estudo a alporquia foi realizada no final do verão, o que provavelmente influenciou negativamente a taxa de enraizamento dos alporques.

Figura 1 - Efeito de diferentes doses do ácido indol butírico (ppm) nas taxas de calejamento e enraizamento dos alporques e sobrevivência dos ramos anelados $(\%)$, número de raízes e comprimento $(\mathrm{cm})$ da maior raiz nos alpor- ques, no número de Quadrastichus sp., de Eurytoma sp., de Sycophila sp. e de galhas/folíolo de Caryocar bra- siliense. 2003-2004. Montes Claros, MG. (médias e erros-padrão).

Figure 1 - Effect of different levels of indol butiric acid (ppm) on the rates of callus formation, root/air layering, survival of girdling shoots, number of rooting of the air layering and largest root lenght/air layering in the air layering, number of Quadrastichus sp., of Eurytoma sp., of Sycophila sp. and numbers of galls/leaflet of Caryocar brasiliense. Montes Claros-MG. 2003-2004. (mean and standard errors). 
Não foram detectadas diferenças significativas também quanto ao número do parasitóide Quadrastichus sp. $(0,87 \pm 0,53 /$ folíolo) (Figura 1) e das características morfológicas externas das galhas nas diferentes doses de AIB, bem assim com ou sem anelamento. A altura e o diâmetro das galhas, em média, foram de 2,25 $\pm 0,25 \mathrm{~mm}$ e 1,50 $\pm 0,15 \mathrm{~mm}$, respectivamente.

Observou-se maior número de adultos do galhador Eurytoma sp. e de seu parasitóide Sycophila sp. na dose de 2.000 ppm de AIB. Já o maior número de galhas foi observado nos tratamentos que foram tratados com AIB, em comparação com o tratamentotestemunha (sem AIB) (Figura 1). $\mathrm{O}$ aumento no número de galhas e de adultos do galhador Eurytoma sp. em maiores doses exógenas de AIB é um indicativo de que esse inseto utiliza, mesmo que em parte, dos hormônios vegetais de crescimento do seu hospedeiro. Contudo, esse hormônio vegetal parece não afetar diretamente o parasitóide Sycophila sp. O aumento observado na sua abundância deve ser influenciado diretamente pelo aumento na abundância do seu hospedeiro galhador. O aumento na concentração de hormônios, incluindo o AIA, pode influenciar o sucesso da indução de galhas (MAPES e DAVIES, 2001). Já foram observadas concentrações de AIA na saliva ou glândulas salivares de espécies seletivas de homópteras (HORI, 1992). Entretanto, o nematóide $M$. arenaria é favorecido por AIB, quando as raízes danificadas de $P$. cerasifera o produzem (ESMENJAUD et al., 1995).

Não se detectou efeito significativo com anelamento na ausência de AIB com o tratamentocontrole (sem anelamento) no número de galhas $(3,18$ $\pm 0,44$ e 3,50 $\pm 0,53 /$ folíolo, respectivamente), de Eurytoma sp. $(9,00 \pm 5,01$ e 11,55 \pm 4,28/folíolo, respectivamente), de Sycophila sp. $(2,11 \pm 1,61 \mathrm{e}$ $3,78 \pm 1,92 /$ folíolo, respectivamente) e de Quadrastichus sp. (0,22 \pm 0,22 e 0,00 \pm 0,00/folíolo, respectivamente). Esse fato possivelmente se deva à concentração de fotoassimilados e de hormônios na região danificada, procedimento realizado para aumentar o calejamento e raízes e, conseqüentemente, o índice de pegamento da alporquia, não havendo, a princípio, concentração desses elementos nas folhas (HARTMANN e KESTER, 1990; POMMER et al., 1991; SIQUEIRA, 1998), o que poderia afetar o ataque de Eurytoma sp. e, em consequiência, de seus parasitóides.

\section{CONCLUSÕES}

A concentração de AIB aumenta o número de galhas e de adultos de Eurytoma sp. Contudo, é necessário aprofundar os estudos para saber até que ponto esse inseto utiliza hormônios da planta para o crescimento da galha, se ele produz hormônio de crescimento vegetal e qual tipo e como esse hormônio pode afetar os parasitóides dos galhadores.

\section{AGRADECIMENTOS}

À taxonomista Dra. Maria Antonieta Pereira de Azevedo (Hymenoptera) (UFRJ), pela identificação do galhador de folha de pequizeiro e de seus parasitóides; e aos revisores anônimos, pelo enriquecimento deste trabalho.

\section{REFERÊNCIAS}

ALONI, R. The induction of vascular tissues by auxin and cytokinin. In: DAVIES, P.J. (Ed.). Plant hormones: physiology, biochemistry, and molecular biology. Dordrecht: Kluwer Academic Publishers, 1995. p.531-547.

ALMEIDA, E. J. et al. Propagação de Dovyalis sp. pelo processo de mergulhia aérea. Revista Brasileira

Fruticultura, v.26, n.3, p.511-514, 2004.

ARAÚJO, F. D. A review of Caryocar brasiliense (Caryocaraceae) - an economically valuable species of the central Brazilian cerrados. Economic Botany, v.9, n.1, p.40-48, 1995.

DOMBROSKI, J. L. D.; PAIVA, R.; CAMARGO, I. P. Efeito de escarificação sobre a germinação do pequizeiro (Caryocar brasiliense Camb.). Revista Brasileira de Fruticultura, v.20, n.1, p.68-73, 1998.

ELIASON, E. A.; POTTER, D.A. Spatial distribution and parasitism of leaf galls induced by Callirhytis cornigera (Hymenoptera: Cynipidae) on pin oak. Environmental Entomology, v.30, p.280-287, 2001.

ESMENJAUD, D. et al. Effect of cutting age on the resistance of Prunus cerasifera (Myrobalan plum) to Meloidogyne arenaria. Journal of Nematology, v.27, n.4, p.634-638, 1995.

R. Árvore, Viçosa-MG, v.31, n.2, p.315-320, 2007 
FERNANDES, G.W. et al. Ant effects on three-trophic level interactions: plant, galls, and parasitoids.

Ecological Entomology, v.24, p.411-415, 1999.

FERNANDES, R. C. et al. Enraizamento de estacas de pequizeiro (Caryocar brasiliense Camb.) sob diferentes doses de AIB. In: SEMANADE INICIAÇÃO CIENTÍFICA, 12., 2003, Belo Horizonte, MG. Resumos... Belo Horizonte: UFMG, 2003. CD-ROM.

HARtMann, H. T.; Kester, D. E. Propagacion de plantas: principios y practicas. México: Compañia Editorial Continental, 1990. 760p.

HORI, K. Insect secretions and their effect on plant grown, with special reference to hemipterans. In: MAPES, C. C.; DAVIES, P. J. Índole-3-acetic acid and ball gall development on Solidago altissima. New Phytologist, v.151, n.1, p.195-202, 1992.

KATIYAR, S.K. et al. Biodiversity of Asian rice gall midge (Orseolia oryzae Wood Mason) from five countries examined by AFLP analysis.

Genome, v.43, p.322-332, 2000.

LANDA, F. S. L. et al. Indução in vitro de calos em explantes foliares de pequizeiro (Caryocar brasiliense Camb.). Ciência e Agrotecnologia, v.24, p.56-63, 2000. (Edição Especial).

MAPES, C. C.; DAVIES, P. J. Indole-3-acetic acid and ball gall development on Solidago altissima. New Phytologist, v.151, n.1, p.195-202, 2001.

MELO, J. T. Fatores relacionados com a dormência de sementes de pequi (Caryocar brasiliense Camb.). 1987. 92f. Dissertação (Mestrado em Ciências Florestais) Escola Superior Luiz de Queiroz, Piracicaba, 1987.
OLIVEIRA, P. S. The ecological function of extrafloral nectaries: herbivore deterrence by visiting ants and reproductive output in Caryocar brasiliense (Caryocaraceae). Functional Ecology, v.11, n.3, p.323-330, 1997.

PACHECO, A. C.; CASTRO, P. R. C.; APPEZZATO-DA-GLÓRIA, B. Aspectos anatômicos do enraizamento da videira muscadínia (Vitis rotundifolia michx.) através de alporquia.

Scientia Agrícola, v.55, n.2., p.210-217, 1998.

PACHECO, M. V. Superação de dormência em sementes de Caryocar brasiliense Camb. Monografia. Montes Claros, NCA/UFMG, 2002.

PEREIRA, A. V.; PEREIRA, E. B. C.; FIALHO, J. F.; JUNQUEIRA, N. T. V.; GOMES, A. C.

Avaliação de métodos de enxertia em mudas de pequizeiro. Boletim de Pesquisa e Desenvolvimento, Embrapa-Cerrado, Planaltina, 2002. 14p.

POMMER, C. V. et al. Efeito do anelamento na maturação de uvas com semente. Revista Brasileira de Fruticultura, v.13, n.3, p.147-150, 1991.

SILVA, D. B. et al. Frutas do cerrado. Brasília: Embrapa Cerrado, 2001. 179p.

SIQUEIRA, D. L. Produção de mudas frutíferas. Viçosa: CPT, 1998. 74p.

WEIS, A. E.; WOLFE, C. L.; GORMAN, W. L. Genotypic variation and integration in histological features of the goldenrod ball gall. American Journal of Botany, v.76, n.10, p.1541-1550, 1989. 